\title{
Distribution and characterization of microplastics in marine sediments from the Montenegrin coast
}

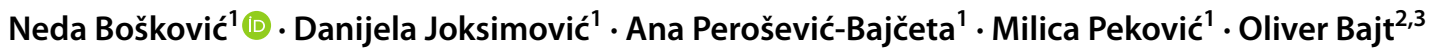

Received: 29 October 2021 / Accepted: 11 February 2022 / Published online: 19 February 2022

(c) The Author(s), under exclusive licence to Springer-Verlag GmbH Germany, part of Springer Nature 2022

\begin{abstract}
Purpose Plastic pollution in the world has led to an abundance of microplastics (MPs) and has been identified as a potential factor that can lead to serious environmental problems, especially in oceans and seas. Information on the current status of MPs pollution along the Montenegrin coast is insufficiently investigated. This study monitors the abundance, distribution, and sources of MPs, and identifies present polymers in the surface sediment of the Montenegrin coast, as well as comparison with previous research.

Materials and methods Ten sampling sites along the Montenegrin coast were selected to collect surface sediment samples. The upper layer of sediment $(0-5 \mathrm{~cm})$ was collected by a Petite ponar grab. The samples were dried, and density separation was performed using a $\mathrm{NaCl}$ solution. The abundance and morphological characteristics of MPs were determined using an optical microscope (DP-Soft software), while FT-IR analysis was done to identify the polymer type.

Results and discussion Microplastics were identified in all sediment samples with an average abundance of $307 \pm 133$ (SD) MPs/kg in dry sediment. The highest abundance of MPs was found in locations in the vicinity of highly populated areas, near wastewater discharges, and areas with high fishing and tourist activities. The most dominant shape types of MPs in all samples were filaments and fragments. The most common colors of MPs were blue and red, while the dominant MPs sizes were $0.1-0.5 \mathrm{~mm}$ and $0.5-1.0 \mathrm{~mm}$. Of the eight identified polymers, PP, PE, and PET were the most common.

Conclusion This study reveals MPs characteristics (abundance, distribution, shape type, colors, size, polymers type) in surface sediment along the Montenegrin coast, as well as the most significant sources of MPs pollution, and provides important data for further research on MPs to identify the effects of MPs pollution on the quality, health, and functionality of the marine environment.
\end{abstract}

Keywords Microplastics · Marine sediment · FT-IR · Montenegro · Adriatic Sea

\section{Introduction}

The term microplastics (MPs) describes any synthetic solid particle or polymeric matrix, with regular or irregular shape, with size ranging from $1 \mu \mathrm{m}$ to $5 \mathrm{~mm}$, primary or secondary

Responsible editor: Elena Romano

Neda Bošković

nedaboskovic93@gmail.com

1 Institute of Marine Biology, University of Montenegro, Put I Bokeljške brigade 68, Kotor 85330, Montenegro

2 Marine Biology Station, National Institute of Biology, Fornače 41, Piran 6330, Slovenia

3 Faculty of Maritime Studies and Transport, University of Ljubljana, Pot pomorscakov 4, Portoroz 6320, Slovenia manufacturing origin and which are insoluble in water (Frias and Nash 2019). Primary MPs are intentionally produced MPs of synthetic polymers that have a wide range of applications including micro-beads incorporated into cosmetic products, resin pellets, and beads used for abrasive blasting (Ryan et al. 2009; Hintersteiner et al. 2015; Wang et al. 2020). Also, primary MPs can originate from the abrasion of synthetic textiles during washing or abrasion of large plastic objects during manufacturing, use, or maintenance such as the erosion of tyres (Sundt et al. 2014). Secondary MPs are formed by the fragmentation of larger pieces of plastic due to the action of various environmental factors (physical, chemical, and biological), which results in the decomposition of plastic into smaller fragments, meaning that macroplastics will fragment into microplastics (Thompson et al. 2004; Arthur et al. 2009; Cole et al. 2011; Yu et al. 2020). 
Side effects of MPs on marine organisms can be physical and chemical. Physical effects are most often related to the size and shape of MPs, while the chemical effects are related to the fact that plastic carries a "cocktail of chemicals" with it (Browne et al. 2011). Among the chemicals present in MPs are those incorporated into plastic polymers during their production (various additives) and those present in water that are adsorbed on the surface of MPs, such as various organic and inorganic pollutants (Godoy et al. 2019).

A large number of studies indicate the presence of plastic as a pollutant in the Adriatic Sea and predict that the Adriatic region will be one of the main areas of plastic accumulation in the Mediterranean, both due to its oceanographic conditions and the high degree of different anthropogenic pressures present in the small area (Liubartseva et al. 2016; Carlson et al. 2017). In the Adriatic Sea, MPs have been found in abiotic and biotic areas, including beaches (Munari et al. 2017), surface waters (Gajšt et al. 2016; Suaria et al. 2016; Vianello et al. 2018), sediment (Vianello et al. 2013; Laglbauer et al. 2014; Renzi and Blašković 2020; Bošković et al. 2021), fish (Avio et al. 2015; Anastasopoulou et al. 2018; Giani et al. 2019), and shellfish (Gomiero et al. 2019; De Simone et al. 2021).

Increased awareness of the growing production and subsequent accumulation of plastic pollution in the environments worldwide has identified MPs as a potential factor contributing to the biodiversity loss in the oceans and seas (Gall and Thompson 2015), which has encouraged the inclusion of various international legislation and projects in the field of marine environment protection. The Marine Strategy Framework Directive (MSFD) states that member states are obliged to take action to achieve and maintain good environmental status and emphasizes the need to obtain as accurate data as possible on the identification, quantification, distribution, and monitoring of environmental MPs, as defined in priority descriptor 10.1.3 (MSFD 2008/56/EC 2008).

The aim of this study is to give additional and more precise information on sources, abundance, and distribution of MPs in surface sediment on the Montenegrin coast. This is important for undertaking available measures to reduce MPs levels in the marine environment, as well as further investigations and monitoring in this field contributing to the efforts of the MSFD.

\section{Materials and methods}

Sediment sampling was performed during the spring of 2021. The study areas for sediment analysis included six locations in Boka Kotorska Bay (Dobrota, Orahovac, Sveta Nedjelja, Tivat, Bijela, and Herceg Novi) and four locations on the coastal area of the open sea (Žanjice, Budva, Bar, and Ada Bojana) (Fig. 1). Sampling locations selected for the research had different geographical positions, morphological and hydrological characteristics, and were influenced by different anthropogenic factors. In Table 1, the basic sampling data are presented.

Surface sediment (upper $5 \mathrm{~cm}$ ) was sampled using a Petite ponar grab, Wildco (composite sample of two samples from one location). Sediment samples after the homogenization which was carried out by conning and quartering (about $500 \mathrm{~g}$ ) were then frozen at $-18{ }^{\circ} \mathrm{C}$ and subjected to a cold drying procedure in a freeze-dryer (CHRIST, Alpha 2-4 LD plus) under a vacuum at $-40{ }^{\circ} \mathrm{C}$ for $48 \mathrm{~h}$. In order to

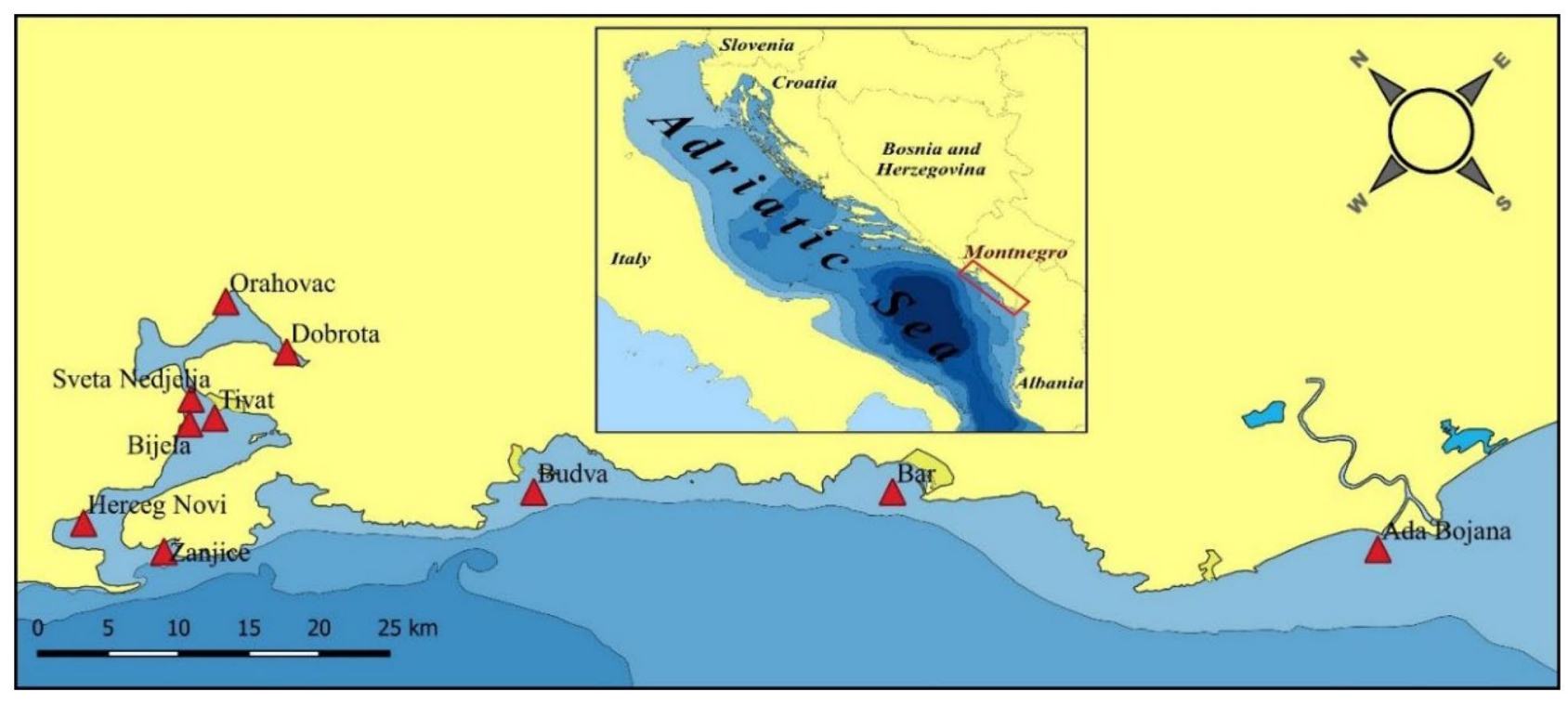

Fig. 1 Sampling locations of surface sediments along the Montenegrin coast 
Table 1 The basic sampling data

\begin{tabular}{|c|c|c|c|c|c|}
\hline Sampling locations & Coordinates & & $\begin{array}{l}\text { Depth of sampling } \\
\text { (m) }\end{array}$ & Date of sampling & Type of sediment ${ }^{*}$ \\
\hline Dobrota & 42.436738 & 18.762041 & 10 & 12.04 .2021 & Slightly gravelly muddy sand \\
\hline Orahovac & 42.486974 & 18.753844 & 20 & 12.04 .2021 & Slightly gravelly muddy sand \\
\hline Sveta Nedjelja & 42.457092 & 18.674193 & 19 & 12.04 .2021 & Gravelly muddy sand \\
\hline Tivat & 42.437744 & 18.677641 & 38 & 12.04.2021 & Slightly gravelly muddy sand \\
\hline Bijela & 42.446168 & 18.658379 & 24 & 12.04 .2021 & Slightly gravelly muddy sand \\
\hline Herceg Novi & 42.446485 & 18.532894 & 42 & 12.04 .2021 & Slightly gravelly muddy sand \\
\hline Žanjice & 42.397888 & 18.566368 & 9 & 12.04 .2021 & Slightly gravelly muddy sand \\
\hline Budva & 42.262911 & 18.833523 & 31 & 16.04 .2021 & Slightly gravelly sand \\
\hline Bar & 42.104562 & 19.057053 & 32 & 16.04 .2021 & Slightly gravelly muddy sand \\
\hline Ada Bojana & 41.863054 & 19.323559 & 12 & 16.04 .2021 & Slightly gravelly sand \\
\hline
\end{tabular}

*According to classification by Folk (1954)

extract MPs from the sediment, a density separation process was applied according to the method proposed by Thompson et al. (2004), using supersaturated $\mathrm{NaCl}$ solution $\left(1.202 \mathrm{~g} \mathrm{~cm}^{-3}\right)$. In a glass jar $(1 \mathrm{~L}), 100 \mathrm{~g}$ of dry sediment and $0.5 \mathrm{~L}$ of concentrated $\mathrm{NaCl}$ solution were added. The sample was manually vigorously shaken for $2 \mathrm{~min}$. After $24 \mathrm{~h}$, the supernatant was decanted through a $63 \mu \mathrm{m}$ steel sieve. The residue (precipitate) for each sample was again subjected to a density separation process. After sieving, the samples were filtered on glass fiber filters of Grade C using a vacuum pump, and then transferred to glass Petri dishes.

In order to visually identify and count the number, determine the shape, color, size, and texture of MPs present in the samples, the samples were analyzed under a microscope. Microplastics are usually divided into four size categories: $<0.1 \mathrm{~mm}, 0.1-0.5 \mathrm{~mm}, 0.5-1.0 \mathrm{~mm}$, and $1.0-5.0 \mathrm{~mm}$ and four types of shapes: fragments, filaments, films, and granules (Galgani et al. 2013). Fragments represent irregularly shaped particles, such as crystals, powder and flakes, rigid, thick, with sharp curved edges. The filaments or fibres are thread-shaped, oblong, may look like strips or have a cylindrical shape. Films are irregularly shaped, thin, flexible and usually transparent compared to fragments. Granules are spherical particles, such as pellets of common resins, spherical microbeads and microspheres (Claessens et al. 2011; Frias and Nash 2019). Even though color is not considered to be crucial to defining MPs, because color differentiation is subjective (Frias and Nash 2019), categorizing MPs according to color is useful to identify potential sources as well as potential contaminations (Hartmann et al. 2019). Visual analysis of MPs was performed using an Olympus SZX16 optical microscope (DP-Soft software). During visual identification, we followed the guidelines proposed by Hidalgo-Ruz et al. (2012) to reduce errors. The MPs on the filters were counted three times, with a discrepancy that did not exceed $5 \%$. Chemical identification of MPs was performed using FT-IR microspectroscopy (Perkin
Elmer Spotlight 200i FT-IR spectroscopy), which allows accurate identification of polymer particles according to their IR spectrum (Thompson et al. 2004; Ng and Obbard 2006; Reddy et al. 2006; Frias et al. 2010; Harrison et al. 2012; Löder and Gerdts 2015). Special care was taken to analyze all types of particles (different colors, shapes, sizes, and structures) using FT-IR spectroscopy. Approximately $30 \%$ of the particles were recorded on FT-IR in each sample individually. Each MPs particle was recorded on FT-IR which was previously photographed and their spectra were preserved. Procedural blanks were performed and collected during all analyses. All results were corrected according to the level of contamination measured during sample processing and analysis, to compensate for external contamination. Abundances of MPs were calculated as the total number of MPs/kg of dry sediment.

\subsection{Quality assurance and quality control}

As contamination in the work can cause significant overestimation of quantitative results (Foekema et al. 2013), in all phases (sampling, transport, drying, density separation, visual, and chemical identification), special care was taken to prevent contamination or cross-contamination of samples. In other words, plastic accessories were avoided during the analysis. Glass and metal utensils/glasswear, washed and rinsed with Milli-Q water, were used during each analysis. We paid special attention to ensure the cleanliness of the laboratory space, especially in regards to dust or other particles. The samples were exposed to air for a minimum time and the analysis procedures were performed in a clean laboratory (fume hood). Work surfaces were cleaned with high-quality ethanol before each process/activity. After filtration, the filters were stored in glass Petri dishes. Pure cotton lab coats were used all the time and synthetic clothing was limited. 


\subsection{Statistical analyses}

Statistical analysis was carried out using principal coordinate analysis (PCO) and cluster analyses with the Premanova Monte Carlo test to verify the significant difference between MPs abundance at different sampling locations $(p<0.05)$. Data were square-root transformed before analysis based on the Bray-Curtis similarity matrices. All data analyses were carried out in PRIMER v7 with PERMANOVA+ software.

\section{Results and discussion}

From the total 348 particles of MPs visually detected in the surface sediments at all locations, $29.31 \%$ of them were analyzed for chemical identification of polymer types using FT-IR spectroscopy. Polymer identification by FT-IR spectroscopy identified eight polymer types: polypropylene (PP, $33.3 \%$ ), polyethylene (PE, 15.7\%), polyethylene terephthalate (PET, 14.7\%), polyamide (PA, 4.9\%), polystyrene (PS, 3.9\%), and acrylate copolymer (AC cop., 2.9\%). Some MPs particles (12.7\%) were identified as polymers, but due to their decomposition during years (aged plastic), it was difficult to determine which polymer category it fell into (because of the high number of different copolymers, which have emerged during years), so we marked them as unidentified polymers (Unid. poly.). The remaining $11.8 \%$ of MPs were non-synthetic materials, cellulose. Cellulose was identified in the surface sediments at 6 of the 10 sampling locations, and these were usually filaments.
Results of chemical identification positively identified $88.2 \%$ of the analyzed MPs as plastic, so the corrected average abundance of MPs in surface sediment from 10 locations along the Montenegrin coast sampled during the spring of 2021 was $307 \pm 133$ (SD) MPs/kg of dry sediment. Figure 2a shows the percentage of polymers in the sediments samples from the Montenegrin coast, and Fig. 2b shows examples of the identified spectra by FT-IR of the most common polymers in the analyzed sediments All sediment samples contained a minimum of three and a maximum of seven different polymer types. Polypropylene and PE were detected in surface sediments at all 10 sampling locations.

Polypropylene and PE were the most common types of polymers in the study done by Bošković et al. (2021). However, in this study, polymers such as PET, PS, and PA were not identified in sediment sampled during the autumn of 2019 (Bošković et al. 2021). Statistical significance $(p<0.05)$ was observed in the presence of different polymers in this study from spring 2021 and the study Bošković et al. (2021) from autumn 2019 (Permanova, Monte Carlo test). Polypropylene and PE are two polymers with very high annual demand and many authors revealed that these polymers are the most frequently found polymers in marine environments around the world (Vianello et al. 2013; Frère et al. 2017; Abidli et al. 2017, 2018; Bošković et al. 2021). They are widely distributed in household appliances, such as packaging, durable textiles, pipes, but are also used for fishing nets, strapping ropes, bottles, packaging bags, etc. (Mistri et al. 2017; Vianello et al. 2018; Fan et al. 2021). Polystyrene, in addition to PP and PE, is one of the most
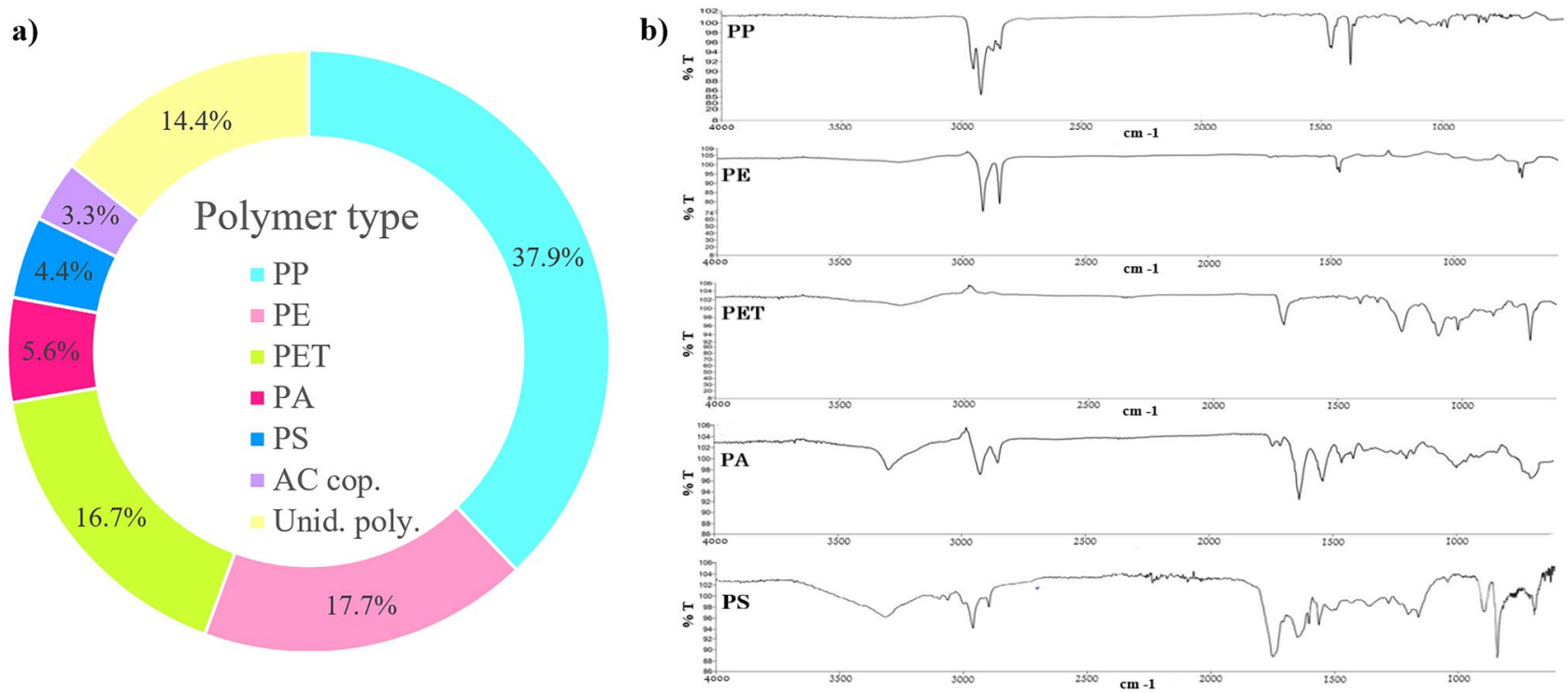

Fig. 2 a Distribution of polymers in surface sediments at all sampling locations and b FT-IR spectroscopy spectra of the most common polymers collected in this study 
commonly used plastics. The use of PS includes protective packaging, containers, lids, bottles, trays, baking cups, and disposable utensils (Maul et al. 2007). Polyethylene terephthalate is used in clothing fibers, for the production of bags, sacks and wrappers, packaging, containers, and also in combination with glass fibers for engineering resins (Oliveira et al. 2020; Fan et al. 2021). Polyamide has commercial application in the production of fabrics, fibers, nets, and films (mainly for food packaging) (Ndiaye and Forster 2007), while the AC cop. is widely used in the cosmetics industry for the production of sunscreens, skin and hair care products, shaving creams, body washes, and moisturizers (Yayayürük 2017).

The mutual PCO and cluster analysis of the distribution of identified polymers with respect to sampling sites and sampling zones are shown in Fig. 3. The results of the PCO show that factors 1 and 2 explain $85.8 \%$ of the total variance in the data matrix, where factor 1 explains $54.3 \%$ of the total variance, and factor 2 explains $31.4 \%$ of the total variance. PCO showed significant correlations between different sampling zones in relation to the polymer distribution $(p<0.05)$. The cluster analysis showed two separate clusters whose mutual similarity and connection is $40 \%$, while within the clusters, individually, it is from 60 to $80 \%$. The first cluster includes sediment samples from the locations Sveta Nedjelja and Žanjice which are connected by a similar presence of the PE as the dominant polymer, followed by AC cop., Unid. poly., and PP. The second cluster includes sediment samples from the locations Ada Bojana, Budva, Herceg Novi, Bijela, Tivat, Orahovac, Dobrota, and Bar and reveals several different types of polymers. Only at the locations of Bijela and Tivat, had PS identified in addition to all other polymers, which is why they are in the subcluster, while Orahovac, Bar, and Dobrota in the subcluster are linked by a similar presence of PA and Unid. poly. in addition to other present being polymers (Fig. 3).

Microplastics were identified at all 10 locations. The average concentrations of MPs in the surface sediments of the Montenegrin coast were in the descending order Bijela $>$ Dobrota $>$ Tivat $>$ Budva $>$ Herceg Novi $>$ Orahovac $>$ Bar $>$ Ada Bojana $>$ Sveta Nedjelja $>$ Žanjice. The overall abundance of MPs at all sampling locations of the Montenegrin coast is shown in Fig. 4.

The abundance of MPs greatly varied with sampling location. The locations characterized by the highest population density, and therefore the greatest anthropogenic influences, the highest concentrations of MPs (Dobrota, Tivat, Bijela, Herceg Novi, and Budva) were recorded. As expected, locations Orahovac, Sveta Nedjelja, and Žanjice, had lower concentrations of MPs, since these locations are not densely populated, except during the summer months when they are tourist hotspots. Lower prevalence of MPs were recorded at Bar and Ada Bojana. This can be explained by the greater scattering of MPs in the areas influenced by the open sea due to greater and stronger actions of currents and waves in comparison to the Bay. Similar observations were made previously by Alomar et al. (2016), Abidli et al. (2018), Korez et al. (2019), Palatinus et al. (2019), and Bošković et al. (2021). Comparing the zones, Boka Kotorska Bay and the coastal part of the open sea, it is concluded that the average
Fig. 3 Graphical representation of the distribution of polymers in the sampled sediments in relation to the locations and sampling zones, $\mathrm{PCO}+$ cluster analysis (PRIMER v7 with PERMANOVA+)

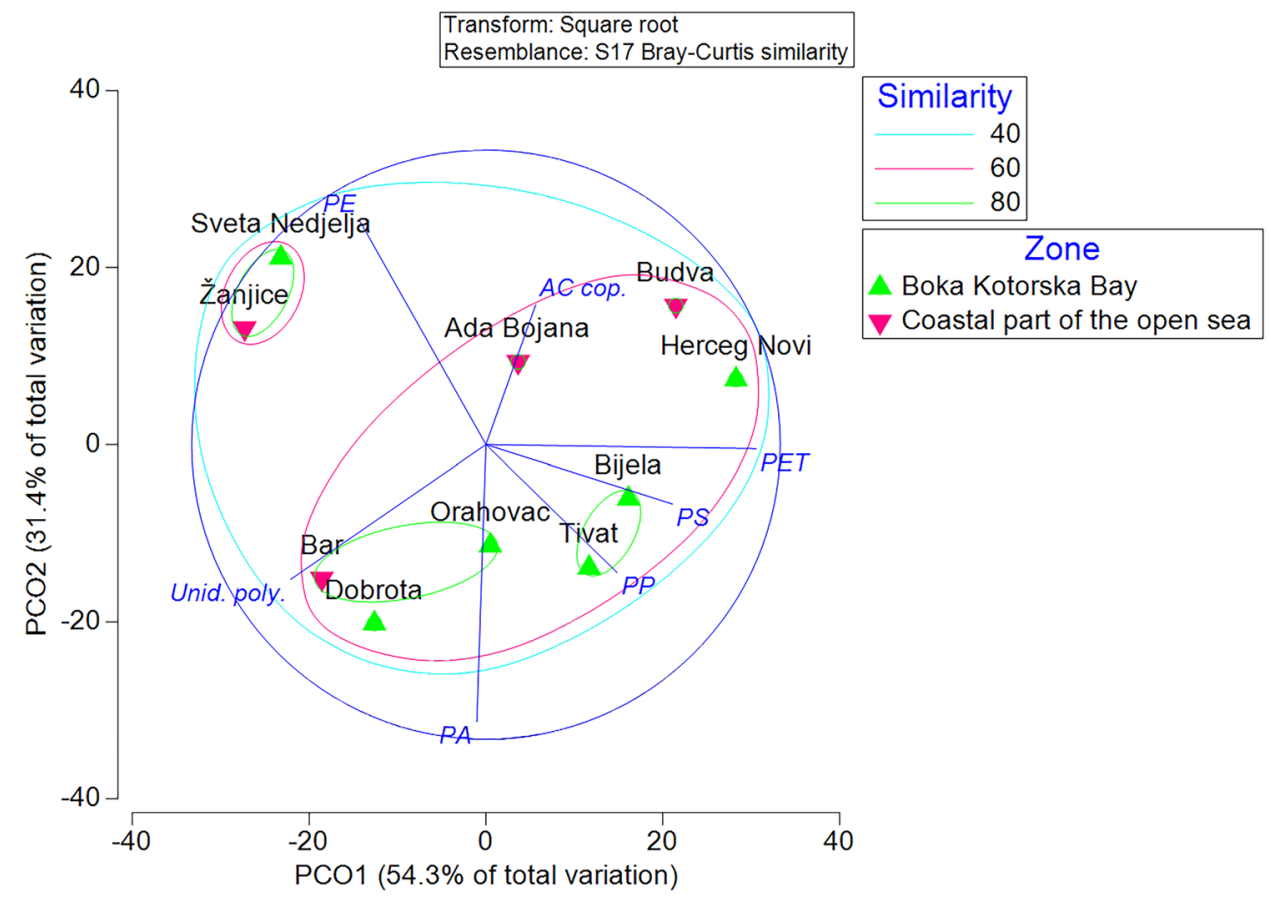


Fig. 4 The abundance of microplastics in surface sediments at 10 sampling locations along the Montenegrin coast

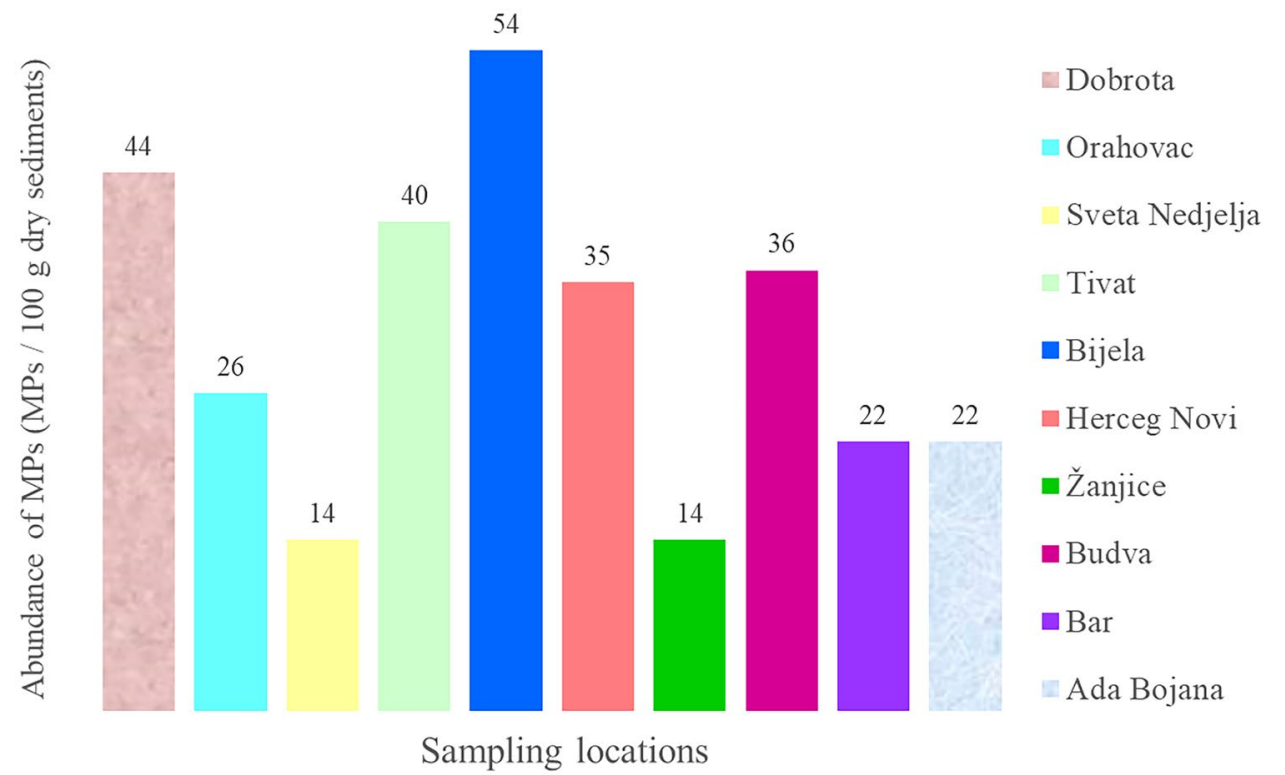

presence of MPs was significantly higher in surface sediments at the locations from the Bay than at the locations on the coastal part of the open sea.

The average number of MPs found in all sediment samples collected in the spring of 2021 was twice as low than that reported for the Montenegrin coast at the same locations during the autumn period of 2019 (Bošković et al. 2021). More precisely, at the locations of Dobrota, Sveta Nedjelja, Herceg Novi, Žanjice, Budva, and Ada Bojana, there were significantly higher concentrations of MPs in the sediment sampled during autumn 2019 compared to sediment sampled in this study (Bošković et al. 2021). It is important to note that in 2019, it was recorded as the best tourist season in Montenegro (Government of Montenegro 2019). The impact of epidemiological measures caused by COVID-19 in 2020 had a noticable effect. During this time, activities such as tourism and fishing lessened. Locations representing port centers such as Tivat, Bijela, and Bar carried out all their usual activities during the pandemic caused by COVID-19. At these locations, higher concentrations of MPs were recorded in this study compared to the study by Bošković et al. (2021). The largest difference in the number of MPs in the sediment from the Montenegrin coast sampled during the autumn period 2019 compared to the spring period 2021 may be a consequence of anthropogenic impact due to increased tourist activity and accumulation of MPs during summer (Claessens et al. 2011; Browne et al. 2011; Abidli et al. 2018). Compared with literature data from the Adriatic and the Mediterranean Sea, the average abundance of MPs found in all sediment samples of this study was lower than that reported for Croatia, Italy, and Spain (Vianello et al. 2013; Alomar et al. 2016; Palatinus et al. 2019; Renzi et al. 2019), and higher than MPs abundance found for sediment samples from Slovenia, Croatia, Italy, and Tunisia (Laglbauer et al. 2014; Blašković et al. 2017; Abidli et al. 2018; Renzi et al. 2018, 2019; Renzi and Blašković 2020). In this study, several factors were observed that can be related to the occurrence and distribution of the MPs contamination in the surface sediments: (1) natural factors, such as plastic properties, meteorological, and hydrodynamic conditions, and (2) anthropogenic factors such as dense populations, tourist, fishing activities, wastewater discharges, solid waste, passenger ships, and harbors. Similar observations were made by Barnes et al. (2009), Browne et al. (2011), Wagner et al. (2014), Abidli et al. (2017), Naji et al. (2017), and Fan et al. (2021).

Microplastics appear in different shape, size, and color. The images of collected MPs in surface sediments from the Montenegrin coast are shown in Fig. 5. The highest proportion of shapes was recorded for filaments $(52.8 \%)$, followed by fragments $(35.5 \%)$, films $(6.5 \%)$, and granules (5.2\%) (Fig. 6a). Filaments and fragments were found at all examined locations, while films and granules were identified at five sampling locations (Dobrota, Sveta Nedjelja, Bijela, Žanjice, and Ada Bojana for films, and Dobrota, Žanjice, Budva, Bar, and Ada Bojana for granules). Sediments from Orahovac, Tivat, and Herceg Novi had all four shape types. Filaments accounted for over $50 \%$ of the total MPs at seven of the 10 sampling locations. Filaments in surface sediments can originate from a wide range of sources, such as peeling of plastic fishing gear, domestic sewage (laundry wastewater), and the industrial production of fabrics and textiles (Mistri et al. 2018; Fan et al. 2021). Abundance of filaments was similar in sediment samples in this study and at the same locations sampled during 2019 (Bošković et al. 2021). Abundance of fragments and films was twice as high in sediment samples in this study compared to the study conducted in 2019, while the abundance of granules was four times higher in the 
Fig. 5 Images of microplastic an Olympus SZX16 optical microscope: filaments (a-d), fragments (e-g), granules $(\mathbf{h}, \mathbf{i})$, and films $(\mathbf{j}, \mathbf{k})$ particles identified by using
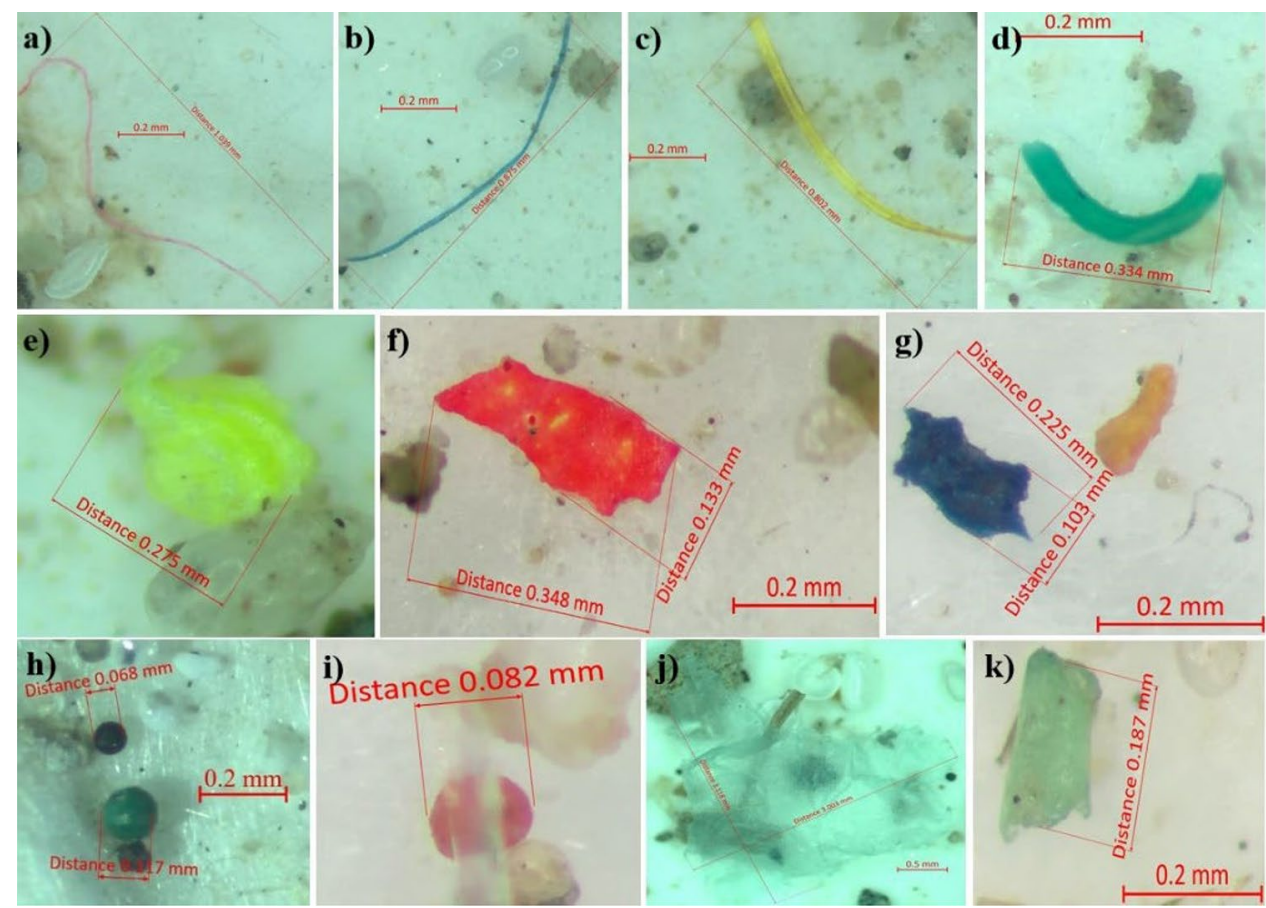

study from 2019 compared to this study (Bošković et al. 2021). Statistical significance $(p<0.05)$ was observed between different sampling years (2021 and 2019) and different zones (Boka Kototska Bay and coastal part of the open sea) in relation to the presence of different shape types of MPs (Permanova, Monte Carlo test). Previous studies reported that filaments were the dominant shape type of MPs in sediments (Thompson et al. 2004; Vianello et al. 2013; Blašković et al. 2017; Mistri et al. 2017, 2018; Bošković et al. 2021). The source of fragments is related to the breakdown of larger plastic debris, films mainly originate from the weathering and cracking of packaging/ bags or plastic wrappers, while granules could originate from various cosmetic products (Claessens et al. 2011; Abidli et al. 2017, 2018; Fan et al. 2021).
In terms of color, there were clear differences in abundance: blue $(37.8 \%)>$ red $(25.1 \%)>$ green $(11.1 \%)>$ black $(10.1 \%)>$ yellow $(7.8 \%)>$ clear $(6.14 \%)$ (Fig. 6b). The majority of filaments were blue (46.9\%), followed by red (16\%), black (15.4\%), clear (14.8\%), yellow (4.94\%), and green $(1.85 \%)$. Fragments were dominated by red (39.4\%), blue $(33.9 \%)$, green $(21.1 \%)$, yellow $(4.6 \%)$, and black $(0.9 \%)$ color. Films by green $(40 \%)$, yellow $(30 \%)$, red (20\%), black (5\%), and clear (5\%). Lastly, granules by black (31.3\%), yellow (31.3\%), red (25\%), and blue (12.5\%) color.

The size distribution of MPs in the studied samples is presented in Fig. 6c. Microplastics were divided into four size categories: $<0.1 \mathrm{~mm}, 0.1-0.5 \mathrm{~mm}, 0.5-1.0 \mathrm{~mm}$, and 1.0-5.0 mm. Small-sized MPs usually have a high abundance because large particles can be split into small ones
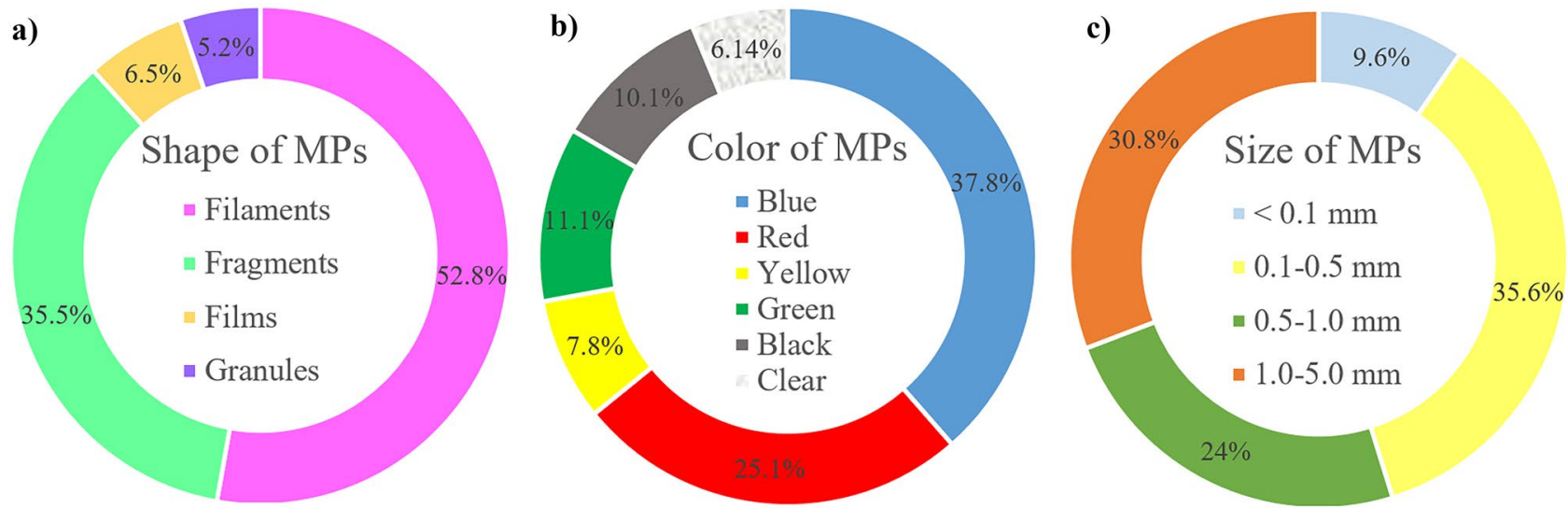

Fig. 6 Distribution of microplastics in surface sediments regarding a shape, $\mathbf{b}$ color, and $\mathbf{c}$ size at all sampling locations 
(Browne et al. 2010; Zhang et al. 2020; Fan et al. 2021). Microplastics in the size category of $0.1-0.5 \mathrm{~mm}(35.6 \%)$ were the most abundant in the sediment samples at all sampling locations, following by sizes $1.0-5.0 \mathrm{~mm}(30.8 \%)$, $0.5-1.0 \mathrm{~mm}(24 \%)$, and $<0.1 \mathrm{~mm}(9.6 \%)$. Differences in the size, shape, and color of MPs could indicate the different origin of the plastics but also the different degrees of accumulation and degradation (Hidalgo-Ruz et al. 2012; Choi et al. 2021).

This study confirms the influence of anthropogenic factors, which is enhanced by tourism. This statement can be approved by the fact that the presence of MPs decreased twice compared to the previous measurement period, during the autumn of 2019, after the best summer tourist season (Bošković et al. 2021). Similarly, Piazzolla et al. (2020) indicated that repeated long-term investigations and seasonal surveys of MPs pollution in sediments give more precise information important for further investigations and monitoring. Additionally, in this study, approximately $30 \%$ of MPs particles were analyzed on FT-IR and compared with the study from autumn of 2019, in which $15 \%$ of MPs particles were analyzed of the total number of identified MPs (Bošković et al. 2021). Therefore, the results from this study give a more precise insight into the presence of different polymer types in the analyzed sediments and are crucial for undertaking prevention measures to reduce MPs levels in the marine environment. Nevertheless, further studies are needed to better evaluate risks for marine biota associated with MPs pollution.

\section{Conclusions}

Microplastics were detected in the surface sediments at all sampling locations along the Montenegrin coast. The average abundance of the MPs was $307 \pm 133$ (SD) MPs/kg of dry sediment. The highest abundance of MPs in surface sediments was detected at the locations in the vicinity of highly populated centers. This result indicates that different human activities might play an important role in MPs pollution around the study area. Additionally, the distribution of MPs depends on meteorological and hydrological factors that can lead to the dispersal or accumulation of MPs in sediments. Filaments and fragments were the dominant shape type of MPs, blue and red were the most common colors, while dominated MPs sizes in all the samples were $0.1-0.5 \mathrm{~mm}$ and $0.5-1.0 \mathrm{~mm}$. Eight different polymers were identified in sediments from the examined locations, the most dominant of which were PP, PE, and PET. Polypropylene and PE were present at all sampling locations. In the future, in order to prevent and control plastic pollution, additional studies should be conducted on the analysis of pollution sources as well as on environmental risks arising from the increased presence of MPs in the marine environment.

Funding This research was funded by the Ministry of Education, Science, Culture, and Sports of Montenegro, grant number PROMIS (No 3173).

\section{Declarations}

Conflict of interest The authors declare no competing interests.

\section{References}

Abidli S, Antunes J, Ferreira JL, Lahbib Y, Sobral P, El Menif NT (2018) Microplastics in sediments from the littoral zone of the north Tunisian coast (Mediterranean Sea). Estuarine Coast Shelf Sci 205:1-9

Abidli S, Toumi H, Lahbib Y, El Menif NT (2017) The first evaluation of microplastics in sediments from the Complex Lagoon Channel of Bizerte (Northern Tunisia). Water Air Soil Pollut 228:262

Alomar C, Estarellas F, Deudero S (2016) Microplastics in the Mediterranean Sea: deposition in coastal shallow sediments, spatial variation and preferential grain size. Mar Environ Res 115:1-10

Anastasopoulou A, Viršek MK, Varezić DB, Digka N, Fortibuoni T, Koren Š, Tutman P (2018) Assessment on marine litter ingested by fish in the Adriatic and NE Ionian Sea macro-region (Mediterranean). Mar Pollut Bull 133:841-851

Arthur C, Baker J, Bamford H (2009) Proceedings of the international research workshop on the occurrence, effects and fate of micro-plastic marine debris, Sept 9-11 (2008) NOAA Technical Memorandum NOS-OR\&R-30. https://marinedebris.noaa.gov/ proceedings-international-research-workshop-microplastic-marinedebris. Accessed 28 Sept 2021

Avio CG, Gorbi S, Regoli F (2015) Experimental development of a new protocol for extraction and characterization of microplastics in fish tissues: First observations in commercial species from Adriatic Sea. Marin Environ Res 111:18-26

Barnes DKA, Galgani F, Thompson R, Barlaz M (2009) Accumulation and fragmentation of plastic debris in global environments. Philos Trans R Soc B Biol Sci 364:1985-1998

Blašković A, Fastelli P, Cižmek H, Guerranti C, Renzi M (2017) Plastic litter in sediments from the Croatian marine protected area of the natural park of Telaščica bay (Adriatic Sea). Mar Pollut Bull 114:583-586

Bošković N, Joksimović D, Peković M, Perošević-Bajčeta A, Bajt O (2021) Microplastics in surface sediments along the Montenegrin Coast, Adriatic Sea: Types, occurrence, and distribution. J Mar Sci Eng 9:841

Browne MA, Crump P, Niven SJ, Teuten E, Tonkin A, Galloway T, Thompson R (2011) Accumulation of microplastic on shorelines woldwide: Sources and sinks. Environ Sci Technol 45:9175-9179

Browne MA, Galloway TS, Thompson R (2010) Spatial patterns of plastic debris along estuarine shorelines. Environ Sci Technol 44:3404-3049

Carlson DF, Suaria G, Aliani S, Fredj E, Fortibuoni T, Griffa A, Russo A, Melli V (2017) Combining litter observations with a regional ocean model to identify sources and sinks of floating debris in a semi-enclosed basin: the Adriatic Sea. Front Mar Sci 4:78

Choi YR, Kim YN, Yoon JH, Dickinson N, Kim KH (2021) Plastic contamination of forest, urban, and agricultural soils: a case 
study of Yeoju City in the Republic of Korea. J Soils Sediments 21:1962-1973

Claessens M, De Meester S, Van Landuyt L, De Clerck K, Janssen C (2011) Occurrence and distribution of microplastics in marine sediments along the Belgian coast. Mar Pollut Bull 62:2199-2204

Cole M, Lindeque P, Halsband C, Galloway TS (2011) Microplastics as contaminants in the marine environment: a review. Mar Pollut Bull 62:2588-2597

De Simone S, Perošević-Bajčeta A, Joksimović D, Beccherelli R, Zografopoulos DC, Mussi V (2021) Microplastics and inorganic contaminants in mussels from the Montenegrin coast. J Mar Sci Eng 9:544

Fan J, Zou L, Zhao G (2021) Microplastic abundance, distribution, and composition in the surface water and sediments of the Yangtze River along Chongqing City, China. J Soils Sediments 21:1840-1851

Foekema EM, De Gruijter C, Mergia MT, van Franeker JA, Murk AJ, Koelmans AA (2013) Plastic in North Sea. Fish Environ Sci Technol 47:8818-8824

Folk RL (1954) The distinction between grain size and mineral composition in sedimentary-rock nomenclature. J Geol 62(4):344-359

Frère L, Paul-Pont I, Rinnert E, Petton S, Jaffré J, Bihannic I, Soudant P, Lambert C, Huvet A (2017) Influence of environmental and anthropogenic factors on the composition, concentration and spatial distribution of microplastics: a case study of the Bay of Brest (Brittany, France). Environ Pollut 225:211-222

Frias JPGL, Nash R (2019) Microplastics: Finding a consensus on the definition. Mar Pollut Bull 138:145-147

Frias JPGL, Sobral P, Ferreira AM (2010) Organic pollutants in microplastics from two beaches of the Portuguese coast. Mar Pollut Bull 60:1988-1992

Gajšt T, Bizjak T, Palatinus A, Liubartseva S, Kržan A (2016) Sea surface micro- plastics in Slovenian part of the northern Adriatic. Mar Pollut Bull 113:392-399

Galgani F, Hanke G, Werner S, De Vrees L (2013) Marine litter within the European Marine Strategy Framework Directive. ICES J Mar Sci 70:1055-1064

Gall SC, Thompson RC (2015) The impact of debris on marine life. Mar Pollut Bull 92:170-179

Giani D, Baini M, Galli M, Casini S, Fossi MC (2019) Microplastics occurrence in edible fish species (Mullus barbatus and Merluccius merluccius) collected in three different geographical sub-areas of the Mediterranean Sea. Mar Pollut Bull 140:129-137

Godoy V, Blázquez G, Calero M, Quesada L, Martín-Lara MA (2019) The potential of microplastics as carriers of metals. Environ Pollut 255:113363

Gomiero A, Strafella P, Øysæd KB, Fabi G (2019) First occurrence and composition assessment of microplastics in native mussels collected from coastal and offshore areas of the northern and central Adriatic Sea. Environ Sci Pollut Res 26:24407-24416

Government of Montenegro (2019) Information on the qualitative and quantitative results of the summer tourist season 2019. https://www.gov.me/en/documents/0a8ff525-edfa-4186-8519c1241 ef638f1. Accessed 30 Sept 2021

Harrison JP, Ojeda JJ, Romero-Gonzalez ME (2012) The applicability of reflectance micro-Fourier-transform infrared spectroscopy for the detection of synthetic microplastics in marine sediments. Sci Tot Environ 416:455-463

Hartmann N, Hüffer T, Thompson RC, Hassellöv M, Verschoor A, Daugaard AE, Wagner M (2019) Are we speaking the same language? Recommendations for a definition and categorization framework for plastic debris. Environ Sci Technol 53:1039-1047

Hidalgo-Ruz V, Gutow L, Thompson RC, Thiel M (2012) Microplastics in the marine environment: a review of the methods used for identification and quantification. Environ Sci Technol 46:3060-3075
Hintersteiner I, Himmelsbach M, Buchberger W (2015) Characterization and quantitation of polyolefin microplastics in personalcare products using high temperature gel-permeation chromatography. Analy Bioanaly Chem 407:1253-1259

Korez S, Gutow L, Saborowski R (2019) Microplastics at the strandlines of Slovenian beaches. Mar Pollut Bull 145:334-342

Laglbauer BJ, Franco-Santos RM, Andreu-Cazenave M, Brunelli L, Papadatou M, Palatinus A, Grego M, Deprez T (2014) Macrodebris and microplastics from beaches in Slovenia. Mar Pollut Bull 89:356-366

Liubartseva S, Coppini G, Lecci R, Creti S (2016) Regional approach to modeling the transport of floating plastic debris in the Adriatic Sea. Mari Pollut Bull 103:115-127

Löder MGJ, Gerdts G (2015) Methodology used for the detection and identification of microplastics - a critical appraisal. Marine Anthrop Litt 201-227

Maul J, Frushour BG, Kontoff JR, Eichenauer H, Ott KH, Schade C (2007) Polystyrene and styrene copolymers. Ullmann's Ency Indust Chem. https://doi.org/10.1002/14356007.a21_615.pub2

Mistri M, Infantini V, Scoponi M, Granata T, Moruzzi L, Massara F, De Donati M, Munari C (2017) Small plastic debris in sediments from the Central Adriatic Sea: Types, occurrence and distribution. Mar Pollut Bull 124:435-440

Mistri M, Infantini V, Scoponi M, Granata T, Moruzzi L, Massara F, De Donati M, Munari C (2018) Microplastics in marine sediments in the area of Pianosa Island (Central Adriatic Sea). Rendiconti Lince 29:805-809

MSFD 2008/56/EC (2008) Marine strategy framework directive of the european parliament and of the council. establishing a framework for community action in the field of marine environmental. Policy J Eur Union. https://eur-lex.europa.eu/legalcontent/EN/TXT/PDF/?uri=CELEX:32008L0056\&from=en. Accessed 20 Sept 2021

Munari C, Scoponi M, Mistri M (2017) Plastic debris in the Mediterranean Sea: Types, occurrence and distribution along Adriatic shorelines. Waste Managment 67:385-391

Naji A, Esmaili Z, Mason SA, Vethaak AD (2017) The occurrence of microplastic contamination in littoral sediments of the Persian Gulf. Iran Environ Sci Pollut Res 24:20459-20468

Ndiaye PA, Forster E (2007) Nylon and bombs: DuPont and the march of modern America. Baltimore: Johns Hopkins University Press, p 304. ISBN 9780801884443

$\mathrm{Ng}$ KL, Obbard JP (2006) Prevalence of microplastics in Singapore's coastal marine environment. Mar Pollut Bull 52:761-767

Oliveira J, Belchior A, da Silva VD, Rotter A, Petrovski Ž, Almeida PL, Lourenço ND, Gaudêncio SP (2020) Marine environmental plastic pollution: Mitigation by microorganism degradation and recycling valorization. Front Mar Sci 7:567126

Palatinus A, Viršek MK, Robič U, Grego M, Bajt O, Šiljić J, Suaria G, Liubartseva S, Coppini G, Peterlin M (2019) Marine litter in the Croatian part of the middle Adriatic Sea: Simultaneous assessment of floating and seabed macro and micro litter abundance and composition. Mar Pollut Bull 139:427-439

Piazzolla D, Cafaro V, de Lucia GA, Mancini E, Scanu S, Bonamano S, Marcelli M (2020) Microlitter pollution in coastal sediments of the northern Tyrrhenian Sea, Italy: Microplastics and fly-ash occurrence and distribution. Estuar Coast Shelf Sci 241:106819

Reddy MS, Basha S, Adimurthy S, Ramachandraiah G (2006) Description of the small plastics fragments in marine sediments along the Alang-Sosiya ship-breaking yard, India. Estuar Coast Shelf Sci 68:656-660

Renzi M, Blašković A (2020) Chemical fingerprint of plastic litter in sediments and holothurians from Croatia: Assessment \& relation to different environmental factors. Mar Pollut Bull 153:110994 
Renzi M, Blašković A, Fastelli P, Marcelli M, Guerranti C, Cannas S, Barone L, Massara F (2018) Is the microplastic selective according to the habitat? Records in amphioxus sands, Mäerl bed habitats and Cymodocea nodosa habitats. Mar Pollut Bull 130:179-183

Renzi M, Cižmek H, Blašković A (2019) Marine litter in sediments related to ecological features in impacted sites and marine protected areas (Croatia). Mar Pollut Bull 138:25-29

Ryan PG, Moore CJ, Van Franeker JA, Moloney CL (2009) Monitoring the abundance of plastic debris in the marine environment. Philos Trans R Soc Lond B Biol Sci 364:1999-2012

Suaria G, Avio CG, Mineo A, Lattin GL, Magaldi MG, Belmonte G, Moore CJ, Regoli F, Aliani S (2016) The Mediterranean Plastic Soup: synthetic polymers in Mediterranean surface waters. Sci Rep 6:37551

Sundt P, Schulze PE, Syversen F (2014) Sources of microplastic - pollution to the marine environment (MEPEX). www.miljodirektoratet.no/ Documents/publikasjoner/M321/M321.pdf. Accessed 5 Jan 2022

Thompson RC, Olsen Y, Mitchell RP, Davis A, Rowland SJ, John AWG, McGonigle D, Russell AE (2004) Lost at sea: Where is all the plastic? Science 304:838

Vianello A, Boldrin A, Guerriero P, Moschino V, Rella R, Sturaro A, Da Ros L (2013) Microplastic particles in sediments of lagoon of Venice, Italy: First observations on occurrence, spatial patterns and identification. Estuar Coast Shelf Sci 130:54-61
Vianello A, Da Ros L, Boldrin A, Marceta T, Moschino V (2018) First evaluation of floating microplastics in the Northwestern Adriatic Sea. Environ Sci Pollut Res 25:28546-28561

Wagner M, Scherer C, Alvarez-Muñoz D, Brennholt N, Bourrain X, Buchinger S, Fries E, Grosbois C, Klasmeier J, Marti T, Rodriguez-Mozaz S, Urbatzka R, Vethaak AD, WintherNielsen M, Reifferscheid G (2014) Microplastics in freshwater ecosystems: What we know and what we need to know. Environ Sci Eur 26:12

Wang S, Chen H, Zhou X, Tian Y, Lin H (2020) Microplastic abundance, distribution and composition in the mid-west Pacific Ocean. Environ Pollut 264:114125

Yayayürük AE (2017) The use of acrylic-based polymers in environmental remediation studies. Acrylic Polymers in Healthcare Intech. London, UK

Yu F, Li Y, Huang G, Yang C, Chen C, Zhou T, Zhao Y, Ma J (2020) Adsorption behavior of the antibiotic levofloxacin on microplastics in the presence of different heavy metals in an aqueous solution. Chemosphere 260:127650

Zhang D, Liu X, Huang W, Li J, Wang C, Zhang D, Zhang C (2020) Microplastic pollution in deep-sea sediments and organisms of the Western Pacific Ocean. Environ Pollut 259:113948

Publisher's Note Springer Nature remains neutral with regard to jurisdictional claims in published maps and institutional affiliations. 